\title{
Validation of diagnosis codes to identify side of colon in an electronic health record registry
}

Patricia Luhn ${ }^{1,3^{*}}$, Deborah Kuk², Gillis Carrigan ${ }^{1}$, Nathan Nussbaum², Rachael Sorg ${ }^{2}$, Rebecca Rohrer², Melisa G. Tucker ${ }^{2}$, Brandon Arnieri', Michael D. Taylor ${ }^{1}$ and Neal J. Meropol ${ }^{2}$

\begin{abstract}
Background: The use of real-world data to generate evidence requires careful assessment and validation of critical variables before drawing clinical conclusions. Prospective clinical trial data suggest that anatomic origin of colon cancer impacts prognosis and treatment effectiveness. As an initial step in validating this observation in routine clinical settings, we explored the feasibility and accuracy of obtaining information on tumor sidedness from electronic health records (EHR) billing codes.

Methods: Nine thousand four hundred three patients with metastatic colorectal cancer (mCRC) were selected from the Flatiron Health database, which is derived from de-identified EHR data. This study included a random sample of 200 mCRC patients. Tumor site data derived from International Classification of Diseases (ICD) codes were compared with data abstracted from unstructured documents in the EHR (e.g. surgical and pathology notes). Concordance was determined via observed agreement and Cohen's kappa coefficient (k). Accuracy of ICD codes for each tumor site (left, right, transverse) was determined by calculating the sensitivity, specificity, positive predictive value (PPV), and negative predictive value (NPV), and corresponding 95\% confidence intervals, using abstracted data as the gold standard.
\end{abstract}

Results: Study patients had similar characteristics and side of colon distribution compared with the full mCRC dataset. The observed agreement between the ICD codes and abstracted data for tumor site for all sampled patients was $0.58(\mathrm{~K}=0.41)$. When restricting to the $62 \%$ of patients with a side-specific ICD code, the observed agreement was $0.84(\mathrm{k}=0.79)$. The specificity $(92-98 \%)$ of structured data for tumor location was high, with lower sensitivity (49-63\%), PPV (64-92\%) and NPV (72-97\%). Demographic and clinical characteristics were similar between patients with specific and non-specific side of colon ICD codes.

Conclusions: ICD codes are a highly reliable indicator of tumor location when the specific location code is entered in the EHR. However, non-specific side of colon ICD codes are present for a sizable minority of patients, and structured data alone may not be adequate to support testing of some research hypotheses. Careful assessment of key variables is required before determining the need for clinical abstraction to supplement structured data in generating real-world evidence from EHRs.

Keywords: Diagnosis code, Metastatic colorectal cancer, Electronic medical record

\footnotetext{
* Correspondence: luhn.patricia@gene.com

${ }^{1}$ Genentech, Inc, South San Francisco, CA, USA

${ }^{3}$ Real World Data-Science (RWD-S) Genentech, a Member of the Roche

Group 1 DNA Way, South San Francisco, CA 94080, USA

Full list of author information is available at the end of the article
}

(c) The Author(s). 2019 Open Access This article is distributed under the terms of the Creative Commons Attribution 4.0 International License (http://creativecommons.org/licenses/by/4.0/), which permits unrestricted use, distribution, and reproduction in any medium, provided you give appropriate credit to the original author(s) and the source, provide a link to the Creative Commons license, and indicate if changes were made. The Creative Commons Public Domain Dedication waiver (http://creativecommons.org/publicdomain/zero/1.0/) applies to the data made available in this article, unless otherwise stated. 


\section{Background}

Historically, prospective randomized clinical trials have served as the "gold standard" for evidence generation in oncology. Given that only a small percentage of cancer patients take part in clinical research studies [1], there is increasing interest in leveraging the data contained in administrative and clinical databases for patients treated outside of clinical trials, as these data can provide guidance for treatment decisions. Such real-world data have the potential to be more representative of patients in routine practice, given that clinical trials tend to enroll highly selected patients who are younger and have fewer comorbidities. Furthermore, real-world data can supplement the results of prospective clinical trials in settings where accrual is difficult due to uncommon clinical or genomic selection criteria. Recently, the Twenty-first Century Cures Act [2] and United States Food and Drug Administration 2018 Goals [3] both highlighted the imperative to understand how real-world data can be optimally used to improve health.

The data contained in electronic health records (EHRs) afford an important opportunity to test hypotheses regarding patterns of care and outcomes in a broadly representative sample of cancer patients. EHR data are characterized by date and may not require third-party primary data collection. However, the impact of real-world data is dependent upon the reliability of specific data elements, their completeness, and the ability to ensure and trace their provenance [4]. Thus, the promise of EHR data can only be realized if each data point is carefully assessed and validated before clinical conclusions are drawn.

As an example of the research application of EHR data, we sought to validate in a real-world setting recent clinical findings from a group of prospective clinical trials in patients with metastatic colorectal cancer (mCRC). Historically, the clinical development of systemic therapies for mCRC has not distinguished patients based on the location of the tumor within the bowel. However, recent analyses have suggested that anatomical side of the colon from which a tumor arises is a prognostic and predictive indicator of survival [5-9]. These studies have indicated that CRCs arising from the left or right side of the colon differ significantly in their clinical characteristics and gene expression profiles [10-13], with rightsided tumors being associated with a worse prognosis [14-16]. Therapeutic outcome also may differ by tumor side, with several analyses reporting differences in benefit with epidermal growth factor receptor and vascular endothelial growth factor antibodies in left- vs rightsided mCRC tumors $[5,6]$. These findings led to a recent international expert panel recommendation that primary tumor location be included as an essential data element in the design and reporting of colon cancer clinical trials [17]. As an initial step in seeking to replicate these findings in a real-world population, we undertook a formal analysis of the ability to obtain information about tumor sidedness from billing codes (International Classification of Disease [ICD] 9/10) in EHRs. The overall goal of this study was to determine the feasibility of using structured diagnostic codes to determine tumor location for patients with $\mathrm{mCRC}$. The formal validation approach described herein may be broadly applied to other clinical contexts where data points from EHRs are being considered for use in outcomes research.

\section{Methods}

\section{Data source}

This validation study was conducted using the nationwide Flatiron Health database, a longitudinal, demographically and geographically diverse database derived from de-identified EHR data. The Flatiron Health database includes data from over 265 cancer clinics, comprised of both community and academic oncology clinics, representing more than 2 million US cancer patients available for analysis. The deidentified patient-level data in the EHRs includes structured data (e.g. billing codes, laboratory measurements, visits, and prescribed drugs) and unstructured data curated via technology-enabled chart abstraction from physicians' notes and other unstructured documents (e.g. physician progress notes, pathology reports).

\section{Patient selection}

From the broader Flatiron Health EHR-derived database, a cohort of mCRC patients was created. Patients were selected for an ICD-code of colon or rectal cancer (153.x, 154.x, C18x, C19x, C20x, or C21x), at least two clinic visits in the Flatiron network that occurred on or after January 1, 2013, and clinical documentation of mCRC. Patients lacking relevant unstructured documents in the Flatiron Health database for abstraction were excluded. Of 9403 patients with confirmed metastatic colon cancer, a random sample cohort of 200 patients who met the above criteria was included in this study. The random sample was selected using a random number generator with a specified seed so that the list of patients is reproducible. As the current analysis focused on side of colon, patients with a confirmed diagnosis of metastatic rectal cancer were excluded from the validation study.

\section{Identification of tumor location}

ICD codes were compared with location identified through human abstraction of unstructured data to establish the quality of ICD-defined tumor location. For both ICD-defined and abstracted tumor location variables, tumors were classified as left side (splenic flexure, descending colon, sigmoid colon, rectosigmoid junction), right side (cecum, ascending colon, hepatic flexure), or transverse (transverse colon). 
Identification of tumor location based upon structured data Data captured in the Flatiron Health EHR-derived database include ICD, 9th and 10th revisions (ICD9 and ICD10; see Table 5 in Appendix) for diagnoses [18]. Whereas some codes can differentiate CRC tumor origin (i.e. ICD9 153.1/ICD10 C18.4: Malignant neoplasm of transverse colon, ICD9 153.7/ICD10 C18.5: Malignant neoplasm of splenic flexure), there is also an unspecified code (ICD9 153.9/ICD10 C18.9: Malignant neoplasm of the colon, unspecified site) that can be used by physicians.

ICD9/10 codes were available from the diagnosis table in the EHR database and were used to classify patients. The full list of codes and categories used is listed in Table 5 in Appendix: A. The date of the ICD code closest to the initial diagnosis date was used to assign side of colon with the following considerations: if a patient had multiple ICD codes that indicated different sides on the same date, and if this date was closest to the diagnosis date, the patient was categorized as having CRC in multiple sites of the colon. If one of the codes was an unspecified code, it was dropped and the specific code was used to classify the patient (e.g. "Left colon, Unspecified colon" became "Left colon"). For patients with no abstracted initial diagnosis date, the first relevant ICD code was selected.

\section{Identification of tumor location based on chart abstraction}

In order to establish the quality of ICD-defined tumor location, ICD codes were compared with location identified through human abstraction of unstructured data. Centrally trained abstractors reviewed all relevant unstructured documents included in the patients' EHR, including pathology reports, physician notes, and surgical notes to identify evidence of the side of colon. To classify a patient, abstractors looked for terms such as "left colon" or "right colon," as well as the specific sites within the colon, as described in Table 5 in Appendix: A.

\section{Statistical methods}

Patient characteristics were summarized using counts and percentages for categorical variables, and medians and interquartile ranges for continuous variables, for the full mCRC dataset (9403 patients) and the 200 randomly selected participants in our validation study. Concordance between structured ICD codes and abstracted diagnosis was determined via observed percent agreement and Cohen's kappa coefficient $(\mathrm{\kappa})$. The concordance analysis assumed no gold standard. Accuracy of ICD codes was determined by calculating the sensitivity, specificity, positive and negative predictive values, and corresponding 95\% confidence intervals, using the abstracted data as the gold standard. "Unspecified colon side" in the unstructured data was treated as "No" for all of these analyses.

\section{Results}

Baseline characteristics for patients in this study $(\mathrm{N}=200)$ were similar to patients in the full $\mathrm{mCRC}$ dataset for all variables examined (Table 1). Half of the validation study patients were male (50\%), and more than half were aged 65 and older (59\%), and had stage IV $\mathrm{mCRC}$ at initial diagnosis (54\%). An additional $28 \%$ had stage III CRC at initial diagnosis. Site-specific ICD codes were available for 5940 (63\%) patients in the parent cohort (Table 2).

When patients with unspecified ICD codes were excluded from the analysis, the distribution of side of colon using

Table 1 Patient characteristics of full EDM registry patients and 200 randomly selected study patients

\begin{tabular}{|c|c|c|}
\hline $\begin{array}{l}\text { Baseline characteristics, } \\
\mathrm{n}(\%)\end{array}$ & $\begin{array}{l}\text { Sampled patients } \\
N=200\end{array}$ & $\begin{array}{l}\text { Parent cohort } \\
N=9403\end{array}$ \\
\hline $\begin{array}{l}\text { Age at metastatic diagnosis } \\
\text { (years), median (IQR) }\end{array}$ & $67.0(57.0-76.0)$ & $66.0(56.0-75.0)$ \\
\hline \multicolumn{3}{|c|}{ Age at metastatic diagnosis category, years } \\
\hline $18-34$ & $2(1.0)$ & $118(1.3)$ \\
\hline $35-49$ & $25(12.5)$ & $1003(10.7)$ \\
\hline $50-64$ & 55 (27.5) & $3162(33.6)$ \\
\hline$\geq 65$ & $118(59.0)$ & $5120(54.5)$ \\
\hline \multicolumn{3}{|l|}{ Sex } \\
\hline Female & $100(50.0)$ & $4385(46.6)$ \\
\hline Male & $100(50.0)$ & 5017 (53.4) \\
\hline Other/Unknown & 0 & $1(0.01)$ \\
\hline \multicolumn{3}{|l|}{ Region } \\
\hline Northeast & $53(26.5)$ & $2630(28.0)$ \\
\hline Midwest & $40(20.0)$ & $1627(17.3)$ \\
\hline South & $71(35.5)$ & $3340(35.5)$ \\
\hline West & $30(15.0)$ & $1470(15.6)$ \\
\hline Other/unknown & $6(3.0)$ & $336(3.6)$ \\
\hline \multicolumn{3}{|l|}{ Practice type } \\
\hline Community & $188(94.0)$ & $8923(94.9)$ \\
\hline Academic & $12(6.0)$ & $480(5.1)$ \\
\hline \multicolumn{3}{|l|}{ Stage at diagnosis } \\
\hline $0-1$ & $5(2.5)$ & $199(2.1)$ \\
\hline$\|$ & $18(9.0)$ & 993 (10.6) \\
\hline III & $55(27.5)$ & $2247(23.9)$ \\
\hline IV & $107(53.5)$ & $5627(59.8)$ \\
\hline Not documented & $15(7.5)$ & $337(3.6)$ \\
\hline Tumor site: Colon & $200(100.0)$ & $9403(100.0)$ \\
\hline \multicolumn{3}{|c|}{ Side of colon (from abstracted data) } \\
\hline Left side & $99(49.5)$ & NA \\
\hline Right side & $67(33.5)$ & NA \\
\hline Transverse colon & $12(6.0)$ & NA \\
\hline Unspecified & $22(11.0)$ & NA \\
\hline
\end{tabular}

EDM Electronic data mart, NA not applicable 
Table 2 Comparison of patient and clinical characteristics based on presence of specific ICD codes

\begin{tabular}{lll}
\hline Characteristic, $n(\%)$ & $\begin{array}{l}\text { Colon cancer patients } \\
\text { with specific ICD codes } \\
\mathrm{N}=5940\end{array}$ & $\begin{array}{l}\text { Colon cancer patients } \\
\text { without specific ICD } \\
\text { codes } \mathrm{N}=3463\end{array}$ \\
\hline $\begin{array}{l}\text { Age at metastatic } \\
\text { diagnosis (years), } \\
\text { median (IQR) }\end{array}$ & $66.0(56.0-75.0)$ & $66.0(57.0-75.0)$ \\
\end{tabular}

Age at metastatic diagnosis, years

$\begin{array}{lll}18-34 & 72(1.2) & 46(1.3) \\ 35-49 & 650(10.9) & 353(10.2) \\ 50-64 & 2014(33.9) & 1148(33.2) \\ \geq 65 & 3204(53.9) & 1916(55.3) \\ \text { Sex } & & \\ \text { Female } & 2771(46.6) & 1614(46.6) \\ \text { Male } & 3169(53.4) & 1848(53.4) \\ \text { Unknown } & 0(0) & 1(<0.1)\end{array}$

Region

$\begin{array}{lll}\text { Northeast } & 1329(22.4) & 826(23.9) \\ \text { Midwest } & 1214(20.4) & 412(11.9) \\ \text { South } & 2263(38.1) & 1074(31.0) \\ \text { West } & 826(13.9) & 643(18.6) \\ \text { Other/unknown } & 308(5.2) & 508(14.7) \\ \text { Year of mCRC diagnosis } & & \\ 2011 & 457(7.7) & 350(10.1) \\ 2012 & 795(13.4) & 602(17.4) \\ 2013 & 1218(20.5) & 838(24.2) \\ 2014 & 1359(22.9) & 792(22.9) \\ 2015 & 1547(26.0) & 679(19.6) \\ 2016 & 564(9.5) & 202(5.8)\end{array}$

Practice type

Community

$5851(98.5)$

$3072(88.7)$

Academic

$89(1.5)$

Stage at diagnosis

$\begin{array}{lll}\text { 0-I } & 115(1.9) & 84(2.4) \\ \text { II } & 629(10.6) & 364(10.5) \\ \text { III } & 1408(23.7) & 839(24.2) \\ \text { IV } & 3639(61.3) & 1988(57.4) \\ \text { Unknown } & 149(2.5) & 188(5.4)\end{array}$

Tumor site

$\begin{array}{lll}\text { Left side }^{\mathrm{a}} & 3061(51.5) & \text { NA } \\ \text { Right side } & 2377(40.0) & \text { NA } \\ \text { Transverse colon } & 477(8.0) & \text { NA } \\ \text { Multiple sides } & 25(0.4) & \text { NA }\end{array}$

Number of visits post diagnosis, median (Q1, Q3)

$\begin{array}{lll}\text { Any } & 31(11,64) & 31(10,70) \\ \text { Lab } & 1(0,6) & 1(0,5) \\ \text { Treatment } & 14(2,34) & 12(1,35)\end{array}$

Table 2 Comparison of patient and clinical characteristics based on presence of specific ICD codes (Continued)

\begin{tabular}{lll}
\hline Characteristic, n (\%) & $\begin{array}{l}\text { Colon cancer patients } \\
\text { with specific ICD codes } \\
N=5940\end{array}$ & $\begin{array}{l}\text { Colon cancer patients } \\
\text { without specific ICD } \\
\text { codes } N=3463\end{array}$ \\
\hline Office & $8(3,18)$ & $9(3,20)$ \\
Other & $0(0,0)$ & $0(0,0)$ \\
Non-facility & $0(0,0)$ & $0(0,0)$ \\
Radiology & $1(1,1)$ & $1(1,1)$ \\
Missing & $21(0.4)$ & $21(0.6)$
\end{tabular}

Line of therapy (ever in database), including maintenance

$\begin{array}{lll}1 \mathrm{~L} & 4864(81.9) & 2729(78.8) \\ 2 \mathrm{~L} & 2252(37.9) & 1341(38.7) \\ 3 \mathrm{~L} & 986(16.6) & 642(18.5) \\ 4 \mathrm{~L} & 399(6.7) & 265(7.7)\end{array}$

$1 \mathrm{~L}$ treatment regimens (non-maintenance)

$\begin{array}{lll}\text { FOLFOX } & 2537(52.2)^{\mathrm{b}} & 1367(50.1)^{\mathrm{b}} \\ \text { FOLFIRI } & 903(18.6)^{\mathrm{b}} & 533(19.5)^{\mathrm{b}} \\ \text { FOLFOXIRI } & 45(0.9)^{\mathrm{b}} & 31(1.1)^{\mathrm{b}} \\ \begin{array}{l}\text { Bevacizumab- } \\ \text { containing }\end{array} & 2736(56.2)^{\mathrm{b}} & 1485(64.4)^{\mathrm{b}} \\ \begin{array}{l}\text { Biomarker status } \\ \text { KRAS tested }\end{array} & \\ \quad & \\ \text { KRAS Positive } & 925(41.1)^{\mathrm{c}} & 2216(64.0) \\ \text { NRAS tested } & 1070(18.0) & 449(43.1)^{\mathrm{c}} \\ \quad \text { NRAS Positive } & 36(4.6)^{\mathrm{c}} & 13(4.2)^{\mathrm{c}} \\ \text { BRAF tested } & 1333(22.4) & 648(18.7) \\ \text { BRAF Positive } & 101(11.7)^{\mathrm{c}} & 38(10.3)^{\mathrm{c}}\end{array}$

$1 \mathrm{~L}$ First-line, FOLFIRI Leucovorin/5-fluorouracil/irinotecan, FOLFOX Leucovorin/ 5-fluorouracil/oxaliplatin, FOLFOXIRI Leucovorin/5-fluorouracil/oxaliplatin/ irinotecan, ICD International Classification of Diseases, $m C R C$ Metastatic colorectal cancer, NA Not applicable, Q1 Quarter 1

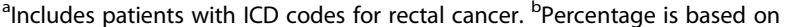

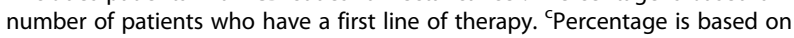
number of patients who have a record of being tested

ICD9/10 codes was similar to the distribution observed using the abstracted tumor site. Of the 200 study patients, $50 \%$ had a left-sided tumor, $34 \%$ had a right-sided tumor, and $6 \%$ had a transverse tumor, based on abstracted data (Table 1 and Table 3). Approximately $4 \%(n=8)$ of patients were considered to have rectal cancer based on ICD codes; however, through chart abstraction these patients had a confirmed diagnosis of colon cancer. Thus, this discrepancy represents misclassification of these patients based on ICD codes alone.

When all 200 study patients were considered, concordance was moderate between the structured (ICD) data and the unstructured (abstracted) data, with an observed agreement of $0.58(\kappa=0.41)$. When patients who were classified as unspecified or rectal in the structured data were removed, the observed agreement was $0.84(\kappa=0.79)$. Seventy-six (38\%) patients were classified as "unspecified" using ICD codes, and 63 of these (83\%) had the side identified through 
Table 3 Sampled patients with side identified by ICD code or by abstraction

\begin{tabular}{llll}
\hline Tumor location, $n(\%)$ & Side identified by ICD code & & $\begin{array}{l}\text { Side identified by } \\
\text { abstraction ( } \mathrm{n}=200)\end{array}$ \\
\cline { 2 - 4 } & $\begin{array}{l}\text { Including unspecified } \\
\text { ICD codes }(\mathrm{n}=200)\end{array}$ & $\begin{array}{l}\text { Excluding unspecified } \\
\text { ICD codes }(\mathrm{n}=124)\end{array}$ & $99(49.5)$ \\
\hline Left colon only & $70(35)$ & $70(56)$ & $67(33.5)$ \\
Right colon only & $35(17.5)$ & $35(28)$ & $12(6)$ \\
Transverse colon only & $10(5)$ & - & $22(11)$ \\
Unspecified colon site only & $76(38)$ & $8(6)$ & 0 \\
Rectum & $8(4)$ & $1(0.8)$ & 0 \\
Right colon and transverse colon & $1(0.5)$ & - & 12 \\
\hline
\end{tabular}

ICD International Classification of Diseases

abstraction. As shown in Table 4, specificity of structured data for tumor location was high, ranging from 92 to $98 \%$. Sensitivity, negative predictive value, and positive predictive value were of lower performance, ranging from 49-63\%, 72-97\%, and 64-92\%, respectively. When patients with non-specific side of colon ICD codes were removed, sensitivity improved to 80\% for all tumor locations. Similar estimates were observed when stratified by stage at initial diagnosis (Stage I-III vs. Stage IV) (Additional file 1: Tables S1-S4).

In an effort to identify potential biases regarding the likelihood that ICD coding for tumor location was present, we compared the clinical characteristics of those patients who had specific diagnosis codes and those who did not. There were no differences in age, stage, sex, or treatment distributions between these two cohorts (Table 2). A gradual increase in the use of specific ICD codes was observed over time, with $57 \%$ of patients diagnosed in 2011 having a specific ICD code, increasing to $74 \%$ of patients diagnosed in 2016, and a higher proportion of use of non-specific ICD codes was seen in academic centers compared with community centers; however, the number of academic sites was small compared to community centers.

\section{Discussion}

This study demonstrates that billing codes are a highly reliable indicator of tumor location, when the specific location code is entered in the EHR. For a sizable minority of mCRC patients, non-specific colon cancer ICD codes are captured in the EHR; thus, structured data for these patients do not indicate tumor side of colon. In these cases, chart abstraction can increase the completeness. If studies are restricted to patients with specific ICD codes, there would likely be minimal bias introduced as the patients with and without specific ICD codes were similar with respect to demographic and clinical characteristics.

A few limitations for this study exist. Although chart abstraction was considered the gold standard, it is subject to errors introduced by abstractors potentially mis-reporting information or by inaccurate information being recorded in the unstructured parts of the EHR. However, chart abstraction is the accepted gold standard for validation studies from administrative claims and other databases, such as EHRs. Additionally, billing codes are collected for the purposes of reimbursement, not for research. Thus, a bias may exist if there are reimbursement incentives based on charges for the treatment based on tumor site. Furthermore, there may be variation in how billing codes are assigned and recorded at the centers in the Flatiron network; however, we did not observe any systematic differences based on centers, with the exception of a higher proportion of patients without specific codes being treated at academic centers. Further studies are needed to validate whether these results are representative of a wider range of data sources, including sources from outside of the US where billing coding practices may differ.

Our analysis demonstrates that ICD codes adequately characterize side of colon for use in studying outcomes for left- versus right-sided colon tumors following specific therapies. However, certain other research questions, e.g. characterizing very small populations such as BRAF-mutant $\mathrm{mCRC}$ patients by variables including primary tumor site, may require a side of colon variable with greater

Table 4 Accuracy of ICD codes $^{\mathrm{a}}$ in sampled patients

\begin{tabular}{lllll}
\hline Accuracy of ICD codes, \% (95\% Cl) & Left & Right & Transverse & Right/Transverse \\
\hline Sensitivity & $63(52,72)$ & $49(37,62)$ & $58(29,84)$ & $52(40,63)$ \\
Specificity & $92(85,96)$ & $98(93,99)$ & $98(94,99)$ & $96(90,98)$ \\
Positive predictive value & $89(78,95)$ & $92(76,98)$ & $64(32,88)$ & $89(76,96)$ \\
Negative predictive value & $72(63,79)$ & $79(72,85)$ & $97(94,99)$ & $75(68,82)$ \\
\hline
\end{tabular}

Cl Confidence interval, ICD International Classification of Diseases

${ }^{\text {a }}$ See Table 5 in Appendix A 
completeness of specific side of colon data. The high specificity of structured data suggests that this augmentation of ICD codes with chart abstracted data may, in some situations, be targeted to only those patients with non-specific CRC ICD codes. For other situations, such as creation of a matched cohort with tumor side as a covariate, abstracting tumor side for all patients in a cohort may be warranted to optimize the quality of the variable.

\section{Conclusions}

Overall, these analyses demonstrate the rigor necessary to characterize an EHR-based variable in terms of reliability and completeness, before engaging in formal testing of clinical hypotheses that could be practicechanging. Such methodological assessments are necessary before conducting large-scale research using variables generated from EHRs.

\section{Appendix}

Table 5 ICD-9/10 colorectal mappings

\begin{tabular}{|c|c|c|}
\hline Diagnosis & $\begin{array}{l}\text { ICD-9 } \\
\text { code }\end{array}$ & $\begin{array}{l}\text { ICD-10 } \\
\text { code }\end{array}$ \\
\hline \multicolumn{3}{|l|}{ Right colon (ascending colon) } \\
\hline Hepatic flexure & 153.0 & C18.3 \\
\hline Cecum & 153.4 & C18.0 \\
\hline Ascending colon & 153.6 & C18.2 \\
\hline \multicolumn{3}{|l|}{ Transverse colon } \\
\hline Transverse colon & 153.1 & C18.4 \\
\hline \multicolumn{3}{|l|}{ Left colon (descending colon) } \\
\hline Descending colon & 153.2 & C18.6 \\
\hline Sigmoid colon & 153.3 & C18.7 \\
\hline Splenic flexure & 153.7 & C18.5 \\
\hline Rectosigmoid junction & 154.0 & C19 \\
\hline \multicolumn{3}{|l|}{ Unspecified colon site } \\
\hline Colon unspecified & 153.9 & C18.9 \\
\hline Malignant neoplasm of appendix vermiformis & 153.5 & N/A \\
\hline Malignant neoplasm of appendix & N/A & C18.1 \\
\hline $\begin{array}{l}\text { Malignant neoplasm of other specified sites of } \\
\text { large intestine }\end{array}$ & 153.8 & N/A \\
\hline $\begin{array}{l}\text { Malignant neoplasm of overlapping sites of } \\
\text { colon }\end{array}$ & N/A & C18.8 \\
\hline \multicolumn{3}{|l|}{ Rectum } \\
\hline Rectum & 154.1 & $\mathrm{C} 20$ \\
\hline $\begin{array}{l}\text { Malignant neoplasm of other sites of rectum, } \\
\text { rectosigmoid junction, and anus }\end{array}$ & 154.8 & N/A \\
\hline Malignant neoplasm of anus, unspecified & N/A & C21.0 \\
\hline Malignant neoplasm of anal canal & N/A & C21.1 \\
\hline $\begin{array}{l}\text { Malignant neoplasm of overlapping sites of } \\
\text { rectum, anus and anal canal }\end{array}$ & N/A & C21.8 \\
\hline
\end{tabular}

\section{Additional file}

Additional file 1: Table S1. Distribution of side identified by ICD code or abstraction for patients with Stage IV disease at diagnosis. Table S2. Distribution of side identified by ICD code or abstraction for patients with Stage I-III disease at diagnosis. Table S3. Accuracy of ICD codes for patients with Stage IV disease at diagnosis. Table S4. Accuracy of ICD codes for patients with Stage I-III disease at diagnosis (DOCX 19 kb)

\section{Abbreviations}

CRC: Colorectal cancer; EHR: Electronic health record; ICD: International Classification of Diseases; mCRC: Metastatic colorectal cancer; NPV: Negative predictive value; PPV: Positive predictive value

\section{Acknowledgements}

Amy P. Abernethy, MD, PhD, reviewed and provided input on the content of this paper during earlier draft stages while she was Chief Medical Officer and Chief Scientific Officer of Flatiron Health. Medical writing assistance was provided by CodonMedical, an Ashfield Business, part of UDG Healthcare PLC, and supported by F Hoffmann-La Roche/Genentech.

\section{Authors' contributions}

$P L, D K, G C, N N, R S, R R, M G T, B A, M D T$, NJM participated in the data collection, data analysis, and drafting of the manuscript. PL, DK, GC, NN, RS, RR, MGT, BA, MDT, NJM also approved the final version of the manuscript to be submitted.

\section{Funding}

This study was supported by F Hoffmann-La Roche/Genentech and Flatiron Health. F Hoffmann-La Roche/Genentech and Flatiron Health participated in the study design; data collection, analysis, and interpretation; and writing of the manuscript.

\section{Availability of data and materials}

The data that support the findings of this study are available from Flatiron Health; however, restrictions apply to the availability of these data, which are subject to the de-identification requirements of the Health Insurance Portability and Accountability Act of 1996 (HIPAA) and implementing regulations, as amended. Practically speaking, in order to share select data and data elements, it will be necessary to first define the methods of storage, transmission, access rights, and scope of intended use prior to making any such data available, and an agreement memorializing the same and applicable re-identification restrictions will be required for the purposes of ensuring compliance with the data license, de-identification, data protection specifications and requirements under HIPAA. Please refer any questions or requests regarding data used in this manuscript to Melisa Tucker (mtucker@flatiron.com) and include Dr. Neal Meropol (nmeropol@flatiron.com) on the email request.

\section{Ethics approval and consent to participate}

Approval of the study protocol (The Flatiron Health Analytic Database; protocol \#15-159) by the New England Institutional Review Board, a WIRBCopernicus company, was obtained prior to study conduct, and included a waiver of informed consent.

\section{Consent for publication}

Not applicable.

\section{Competing interests}

$\mathrm{PL}, \mathrm{GC}, \mathrm{BA}$, and MDT report employment with, and stock ownership in, Genentech, Inc.

DK, NN, RS, RR, MGT, and NJM report employment with Flatiron Health, Inc., which is an independent subsidiary of the Roche Group. NJM, MGT, NN, RR, $\mathrm{RS}$, and DK report equity interest in Flatiron and Roche.

\section{Author details}

${ }_{1}^{1}$ Genentech, Inc, South San Francisco, CA, USA. ${ }^{2}$ Flatiron Health, New York, NY, USA. ${ }^{3}$ Real World Data-Science (RWD-S) Genentech, a Member of the Roche Group 1 DNA Way, South San Francisco, CA 94080, USA. 
Received: 17 August 2018 Accepted: 15 August 2019

Published online: 19 August 2019

\section{References}

1. Murthy VH, Krumholz HM, Gross CP. Participation in cancer clinical trials; race-, sex-, and age-based disparities. JAMA. 2004;291:2720-6.

2. United States Food and Drug Administration. Real-world data and evidence in drug development. 2017; https://www.fda.gov/downloads/drugs/ developmentapprovalprocess/smallbusinessassistance/ucm572939.pdf. Accessed 17 July 2018.

3. United States Food and Drug Administration. PDUFA reauthorization performance goals and procedures fiscal years 2018 through 2022. 2018; https://www.fda.gov/downloads/forindustry/userfees/ prescriptiondruguserfee/ucm511438.pdf. Accessed 17 July 2018.

4. Miksad RA, Abernethy AP. Harnessing the power of real-world evidence (RWE): a checklist to ensure regulatory-grade data quality. Clin Pharmcol Ther. 2018;103:202-5.

5. Arnold D, Lueza B, Douillard JY, et al. Prognostic and predictive value of primary tumour side in patients with RAS wild-type metastatic colorectal cancer treated with chemotherapy and EGFR directed antibodies in six randomised trials. Ann Oncol. 2017;28:1713-29.

6. Loupakis F, Yang D, Yau L, et al. Primary tumor location as a prognostic factor in metastatic colorectal cancer. J Natl Cancer Inst. 2015;107:1-9.

7. Venook AP. Metastatic colorectal cancer: lessons learned, future possibilities. J Natl Compr Canc Netw. 2016;14(5 Suppl):666-8.

8. Venook AP. Right-sided vs left-sided colorectal cancer. Clin Adv Hematol Oncol. 2017;15:22-4.

9. Weiss JM, Pfau PR, O'Connor ES, et al. Mortality by stage for right- versus left-sided colon cancer: analysis of surveillance, epidemiology, and end results - Medicare data. J Clin Oncol. 2011;29:4401-9

10. Meza R, Jeon J, Renehan AG, et al. Colorectal cancer incidence trends in the United States and United Kingdom: evidence of right- to left-sided biological gradients with implications for screening. Cancer Res. 2010;70: 5419-29.

11. Missiaglia E, Jacobs B, D'Ario G, et al. Distal and proximal colon cancers differ in terms of molecular, pathological, and clinical features. Ann Oncol. 2014:25:1995-2001.

12. Benedix F, Kube R, Meyer F, et al. Comparison of 17,641 patients with rightand left-sided colon cancer: differences in epidemiology, perioperative course, histology, and survival. Dis Colon Rectum. 2010;53:57-64.

13. Meguid $R A$, Slidell $M B$, Wolfgang $C L$, et al. Is there a difference in survival between right- versus left-sided colon cancers? Ann Surg Oncol. 2008;15: 2388-94.

14. Petrelli F, Tomasello G, Borgonovo K, et al. Prognostic survival associated with left-sided vs right-sided colon cancer: a systematic review and metaanalysis. JAMA Oncol. 2016 [e-published ahead of print. https://doi.org/10.1 001/jamaoncol.2016.4227.

15. Modest DP, Schulz C, von Weikersthal LF, et al. Outcome of patients with metastatic colorectal cancer depends on the primary tumor site (midgut vs. hindgut): analysis of the FIRE1-trial (FuFIRI or mIROX as first-line treatment). Anticancer Drugs. 2014;25:212-8.

16. Yahagi $M, O$ ababayashi $\mathrm{K}$, Hasegawa $\mathrm{H}$, et al. The worse prognosis of rightsided compared with left-sided colon cancers: a systematic review and meta-analysis. J Gastrointest Surg. 2016;20:648-55.

17. Goey KKH, Sørbye H, Glimelius B, et al. Consensus statement on essential patient characteristics in systemic treatment trials for metastatic colorectal cancer: supported by the ARCAD group. Eur J Cancer. 2018;100:35-45.

18. Centers for Disease Control and Prevention (CDC) International Classification of Diseases. https://www.cdc.gov/nchs/data/dvs/icd10fct.pdf. Accessed 17 July 2018

\section{Publisher's Note}

Springer Nature remains neutral with regard to jurisdictional claims in published maps and institutional affiliations.

Ready to submit your research? Choose BMC and benefit from:

- fast, convenient online submission

- thorough peer review by experienced researchers in your field

- rapid publication on acceptance

- support for research data, including large and complex data types

- gold Open Access which fosters wider collaboration and increased citations

- maximum visibility for your research: over $100 \mathrm{M}$ website views per year

At $\mathrm{BMC}$, research is always in progress.

Learn more biomedcentral.com/submissions 